\title{
ANALISIS NILAI VELOCITY ENCODING TERHADAP INFORMASI CITRA MAGNETIC RESONANCE VENOGRAPHY PADA PENDERITA TUMOR KEPALA
}

\section{ANALYSIS OF VELOCITY ENCODING VALUE TO MAGNETIC RESONANCE VENOGRAPHY IMAGE INFORMATION ON BRAIN TUMOR PATIENT}

\author{
Zita Hadiah Pratami ${ }^{1)}$, Sudiyono ${ }^{2)}$, Yeti Kartikasari ${ }^{3)}$ \\ ${ }^{1)}$ Dr. Moewardi Surakarta Hospital \\ 2) 3) Health Polytechnics of Semarang-Indonesia \\ e-mail: zita_hpratami@yahoo.co.id
}

\begin{abstract}
Background: Brain Magnetic Resonance Venography (MRV) is a MRI examination of veins without contrast media. Phase Contrast (PC) MRV sequences uses phase shift protons that flow along the magnetic gradient into needed area (Field Of View). PC MRV sequences use bipolar gradient to compensate the proton spin speed by adjusting the amplitude. The study aims to determine the Velocity encoding Value (VENC) to MRV image information on brain tumor patient and to determine the best image information through a technic to visualize the veins in brain tumor patient.

Methods: This study was a quantitative study with quasi experimental approach. Data were collected in Radiology Department of Dr. Moewardi Surakarta Hospital on May to June 2016. Data was collected using questionnaire filled by three respondents. Data were analyzed statiscally using Friedman test and Wilcoxon test to determine the difference of value of Velocity Encoding (VENC) between $10 \mathrm{~cm} / \mathrm{sec}, 15$ $\mathrm{cm} / \mathrm{sec}, 20 \mathrm{~cm} / \mathrm{sec}$, as well the mean rank test used to find out the best image information.

Results: The statistical test showed that there were significant differences in image information of MRV, between VENC $10 \mathrm{~cm} / \mathrm{sec}, 15$ $\mathrm{cm} / \mathrm{sec}$ and $20 \mathrm{~cm} / \mathrm{sec}$ with p value was $0.032(\mathrm{p}<0,05)$. The best result of MRV image information was when VENC value of $20 \mathrm{~cm} / \mathrm{sec}$ used, indicated by the mean rank which was 2.83 .

Conclusion: There were significant differences of MRV image information between VENC $10 \mathrm{~cm} / \mathrm{sec}, 15 \mathrm{~cm} / \mathrm{sec}$ and $20 \mathrm{~cm} / \mathrm{sec}$. The best result of MRV image information was when VENC value of $20 \mathrm{~cm} / \mathrm{sec}$ used, to visualize better anatomy of the veins, so that the presence of tumor thrombus in the veins can be ensured.
\end{abstract}

Keywords: MRI, MRV, phase contrast, bipolar gradient,velocity encoding

\section{PENDAHULUAN}

Sekuen MRI untuk memvisualkan sirkulasi vena adalah Magnetic Resonance Venography (MRV). Menurut Hartsdale, MRV sangat effektif untuk mengevaluasi diferensiasi trombus tumor. Phenomenon of flow void merupakan keunggulan MRI untuk menggambarkan struktur pembuluh darah tanpa menggunakan media kontras. Phase Contrast (PC) merupakan dasar MRV, yaitu memanfaatkan perubahan saat pergeseran fase (phase shift) dari proton yang mengalir sepanjang gradien magnet menuju daerah yang diinginkan (Field of View ) untuk mendapatkan informasi citra. Sekuen PC MRV menggunakan bipolar gradient untuk mengkompensasi kecepatan proton. Pengaturan bipolar gradient menggunakan Velocity Encoding tecnique (VENC) yaitu teknik yang mengatur amplitude bipolar gradient agar sesuai dengan kecepatan aliran proton dalam pembuluh darah. Satuannya adalah $\mathrm{cm} /$ detik. Menurut Westbrook nilai VENC untuk sekuen PC MRV adalah $20-30 \mathrm{~cm} /$ detik. Penelitian sebelumnya menyarankan nilai VENC $15 \mathrm{~cm} / \mathrm{dt}$ untuk menvisualkan gangguan aliran di Sinus Transversal pada penderita idiopathic intracranial hypertension (IIH) dan Multiple Sclerosis. Sedangkan di RSUD dr Moewardi Surakarta menggunakan nilai VENC $10 \mathrm{~cm} / \mathrm{dt}$ untuk memvisualkan kejelasan gangguan aliran di pembuluh darah vena kepala. Sehingga penulis merasa tertarik untuk meneliti lebih mendalam tentang nilai VENC dan variasinya, untuk menentukan nilai VENC yang bisa menampilan informasi citra terbaik sebagai standar sekuen PC MRV pada kasus tumor kepala.

Tujuan penelitian ini untuk mengetahui perbedaan informasi citra Magnetic Resonance Venography (MRV) pada penderita tumor kepala dengan variasi nilai Velocity Encoding (VENC). Serta untuk mengetahui informasi citra yang paling baik pada Magnetic Resonance Venography (MRV) dengan variasi nilai VelocityEncoding (VENC) melalui pendekatan teknis untuk memvisualisasikan pembuluh vena pada penderita tumor kepala.

\section{METODE}

Jenis penelitian adalah kuantitatif dengan pendekatan eksperimental, yang bertujuan untuk mengetahui perbedaan informasi citra MRV pada VENC $10 \mathrm{~cm} / \mathrm{dt}, 15 \mathrm{~cm} / \mathrm{dt}$ dan 20 $\mathrm{cm} / \mathrm{dt}$ tanpa menggunakan media kontras. Disain penelitian adalah eksperimental kuasi yaitu penelitian eksperimental dengan pengambilan sampel secara utuh bukan acak selama masa penelitian (Hastjarjo, 2008). Obyek penelitian adalah penderita tumor kepala,dan tidak bergantung lokasi tumor. 
Kelompok eksperimen adalah sekuen PC MRV menggunakan VENC $15 \mathrm{~cm} / \mathrm{dt}$ dan VENC $20 \mathrm{~cm} / \mathrm{dt}$, sedangkan kelompok pengontrol adalah sekuen PC MRV menggunakan $10 \mathrm{~cm} / \mathrm{dt}$.

Tempat penelitian di Instalasi Radiologi Rumah Sakit Umum Daerah dr Moewardi. Waktu pengambilan data pada bulan bulan Mei - Juni 2016. Populasi dan sampel penelitian adalah seluruh citra MRV otak. Sampel dari penelitian ini adalah 3 kelompok sampel berpasangan (45 seri) citra PC MRV dengan VENC $10 \mathrm{~cm} / \mathrm{dt}, 15 \mathrm{~cm} / \mathrm{dt}, 20 \mathrm{~cm} / \mathrm{dt}$ pada 15 penderita dengan kriteria laki laki/perempuan dewasa berusia 30 tahun ke atas dengan kelainan tumor kepala. Subyek penelitian adalah 3 dokter spesialis radiologi yang mempunyai kompetensi dan berpengalaman lebih dari 5 tahun dalam memberikan expertise MRI, yang bertindak sebagai responden dalam menilai informasi citra MRV hasil eksperimen.

Penulis memperoleh data dengan cara melakukan pemeriksaan MRV sebanyak 3 kali pada 15 penderita, masingmasing menggunakan VENC $10 \mathrm{~cm} / \mathrm{dt}, 15 \mathrm{~cm} / \mathrm{dt}$, dan 20 $\mathrm{cm} / \mathrm{dt}$. Penelitian menggunakan parameter terkontrol seperti Time Repetion, Time Echo, flip angle, field of view, Slicethickness, matriks, Number of exitation, dan Gap. Kemudian informasi citra didokumentasikan ke dalam DVD$\mathrm{R}$ yang kemudian dinilai secara kuantitatif melalui kuesioner. Kuesioner berisi pertanyaan seputar informasi citra tentang pembuluh darah vena di kepala. Informasi tersebut didapatkan dengan cara penulis membagikan kuesioner kepada dokter spesialis radiologi yang berpengalaman dalam mengekspertise MRI.

Teknik pengambilan data dengan melakukan prosedur pembuatan citra MRV otak. Prosedur MRV otak dimulai dengan tahap persiapan, Penderita atau keluarganya mengisi informed consent. Kemudian dilakukan prescreening pemeriksaan MRI. Penderita dianjurkan mengenakan baju pasien, melepas benda yang mengandung logam seperti gigi palsu, anting, jepit rambut dan buang air kecil sebelum dilakukan pemeriksaan.Penderita diberikan penjelasan bahwa pemeriksaan memakan waktu sekitar 30 menit, menimbulkan suara bising dan kepala tidak boleh digerakkan selama pemeriksaan berlangsung, dan yang terakhir penderita dipasangkan penutup telinga.

Setelah dilakukan tahap persiapan, kemudian dilanjutkan registrasi sebagai penderita. Pada monitor workstation diisi data penderita meliputi : nomor pemeriksaan, nama, umur, jenis kelamin, berat badan, nomor rekam medis dan jenis pemeriksaan, pemilihan protokol pemeriksaan.

Data-data pasien yang sudah diregistrasi kemudian dilanjutkan pada pembuatan citra MRV. Pertama koil RF head dipasangkan di meja pemeriksaan. Kemudian penderita diposisikan tidur telentang di atas meja pemeriksaan, dengan kepala dan leher tepat diatas permukaan koil. Posisi head first terhadap bore magnet. Lampu penunjuk longitudinal dan vertikal tepat di glabela. Setelah penderita di dalam bore magnet, lakukan scanning untuk mendapatkan localizer potongan sagital, coronal dan axial. Dibuat sekuen PC MRV dengan menempatkan FOV meliputi kepala dan leher. Menggunakan nilai VENC $10 \mathrm{~cm} / \mathrm{dt}$ untuk mengatur amplitudo bipolar gradien berdasarkan kecepatan aliran darah. Dibuat sekuen PC MRV menggunakan nilai VENC $15 \mathrm{~cm} / \mathrm{dt}$ untuk mengatur amplitudo bipolar gradien. Dibuat sekuen PC MRV menggunakan nilai VENC $20 \mathrm{~cm} / \mathrm{dt}$ untuk mengatur amplitudo bipolar gradien. Oleh perangkat lunak komputer berupa Maximum Intencity Projection (MIP) hasil scanning diolah menjadi citra 3 dimensi. Setelah selesai scanning, penderita dipersilahkan turun dari meja pemeriksaan dan mengganti pakaian. Prosedur yang sama dilakukan pada 15 penderita. Hasil citra 3 dimensi MRV seluruh penderita dibuat 6 tampilan gambar dengan perputaran $30^{\circ}$ untuk memudahkan mengevaluasi setiap sinus, direkam dalam 1 DVD.

Prosedur penilaian citra dilakukan oleh 3 dokter spesialis radiologi dan dimohon untuk mencermati citra MRV dari masing-masing penderita yang telah direkam dalam satu DVD pada layar monitor komputer dengan tidak disertakan keterangan apapun, baik identitas, parameter yang digunakan dan hanya diberi nomor seri citra. Penilaian dilakukan dengan memberikan tanda cek $(\sqrt{ })$ pada kuesioner yang disediakan sesuai dengan petunjuk, Kuesioner berisi penilaian terhadap informasi citra meliputi kejelasan pembuluh darah vena pada Sinus sagitalis superior, Sinus Rectus, Sinus transversum, Vena Galen, Sinus Sigmoid, Vena Jugularis.

Semua data statistik yang diperoleh dari hasil kuesioner terhadap responden dianalisa dengan perangkat lunak SPSS 16,0 dengan perincian sebagai berikut : Hasil data dikumpulkan dari penilaian responden dianalisis dengan menggunakan uji statistik non parametrik Friedman karena data berupa data ordinal dengan sampel lebih dari $2(K$ sampel) untuk pengujian terhadap hipotesa dan melihat tingkat perbedaan informasi citra. Untuk mengetahui perbedaan lebih detil terhadap informasi citra MRV pada velocity encoding 10 $\mathrm{cm} / \mathrm{dt}$ dan $15 \mathrm{~cm} / \mathrm{dt}, 10 \mathrm{~cm} / \mathrm{dt}$ dan $20 \mathrm{~cm} / \mathrm{dt}$, serta $15 \mathrm{~cm} / \mathrm{dt}$ dan $20 \mathrm{~cm} / \mathrm{dt}$ dengan menggunakan uji Wilcoxon berdasarkan nilai signifikansinya. Dengan mengetahui mean rank dan nilai signifikannya, maka jika $\mathrm{p}<0,05$ artinya Ha diterima yang berarti ada perbedaan informasi citra MRV dengan variasi velocity encoding $10 \mathrm{~cm} / \mathrm{dt}, 15 \mathrm{~cm} / \mathrm{dt}, 20 \mathrm{~cm} / \mathrm{dt}$. Jika p $>0.05$ maka Ho diterima tidak ada perbedaan informasi citra MRV dengan variasi velocity encoding $10 \mathrm{~cm} / \mathrm{dt}, 15 \mathrm{~cm} / \mathrm{dt}, 20$ $\mathrm{cm} / \mathrm{dt}$. Untuk mengetahui keseluruhan informasi citra yang paling baik pada pemeriksaan MRV dengan variasi velocity encoding $10 \mathrm{~cm} / \mathrm{dt}, 15 \mathrm{~cm} / \mathrm{dt}, \quad 20 \mathrm{~cm} / \mathrm{dt}$ menggunakan uji statistik non parametrik Friedman dengan melihat nilai mean rank yang tertinggi.

\section{HASIL}

Hasil penelitian dengan membuat citra MRV terhadap 15 pasien. Tiap variasi VENC dibuat 6 tampilan gambar dengan perputaran $30^{\circ}$ untuk memudahkan mengevaluasi setiap sinus. Selanjutnya seluruh hasil citra dilakukan penilaian oleh 3 orang dokter spesialis radiologi yang telah berpengalaman membaca citra MRV minimal selama 5 tahun dengan menggunakan ceklist yang terdiri dari anatomi sinus sagitalis superior, sinus rectus, sinus transversum, Vena of Galen, sinus sigmoid, vena Jugularis 


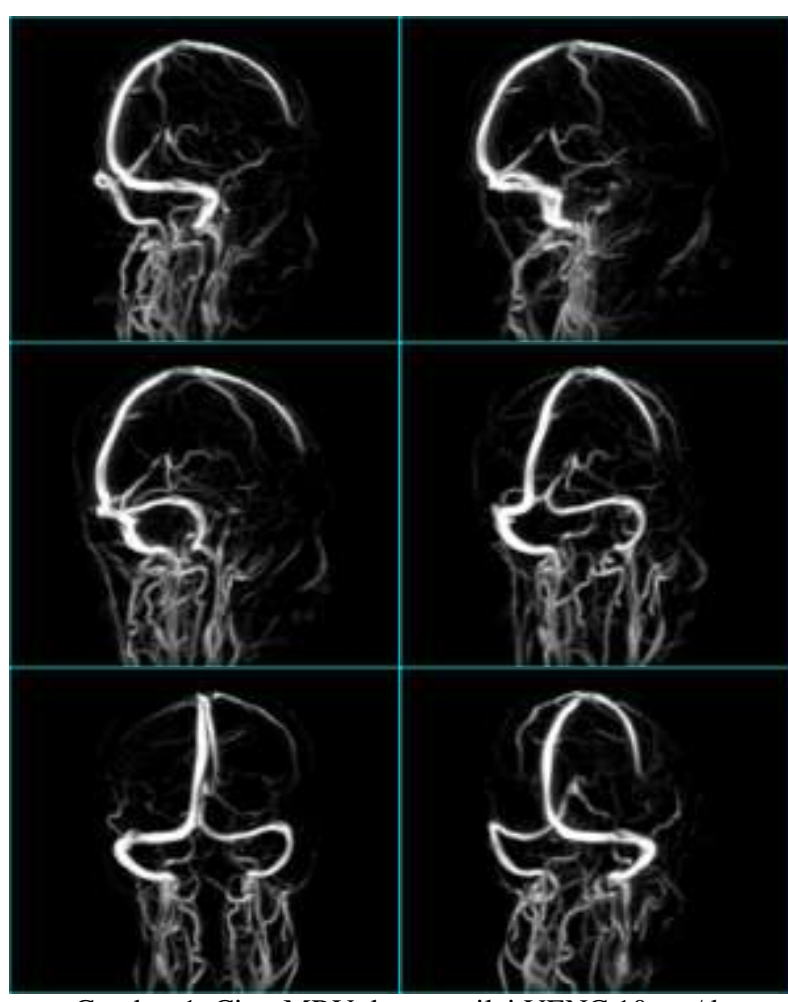

Gambar 1. Citra MRV dengan nilai VENC $10 \mathrm{~cm} / \mathrm{dt}$

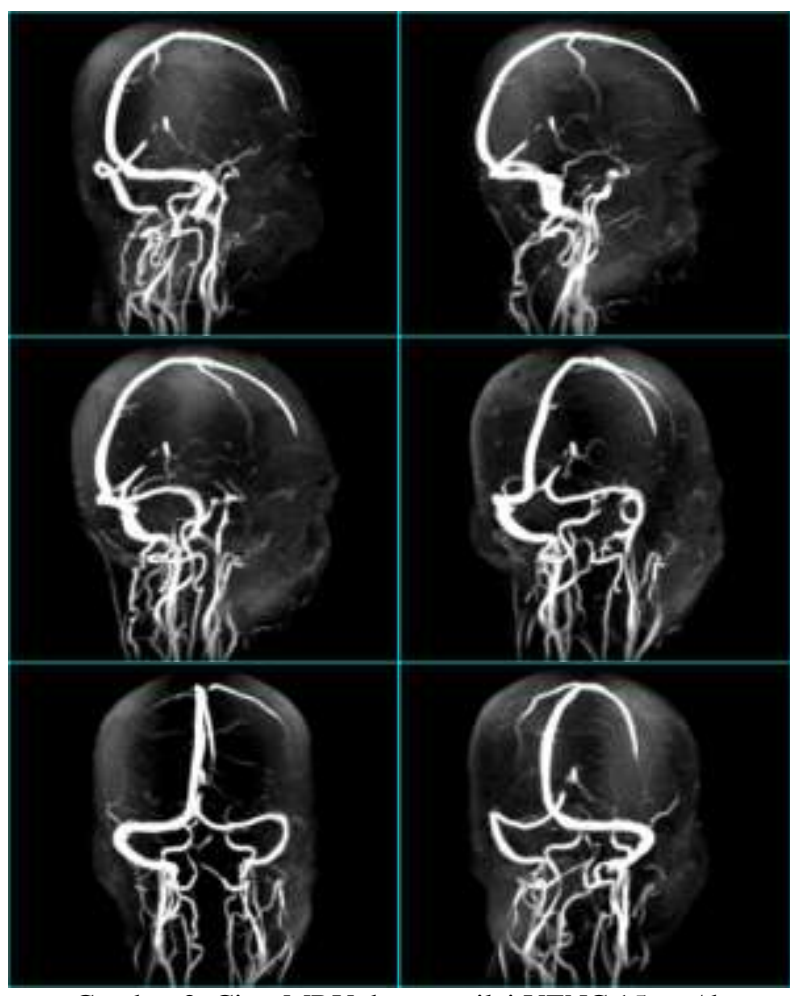

Gambar 2. Citra MRV dengan nilai VENC $15 \mathrm{~cm} / \mathrm{dt}$

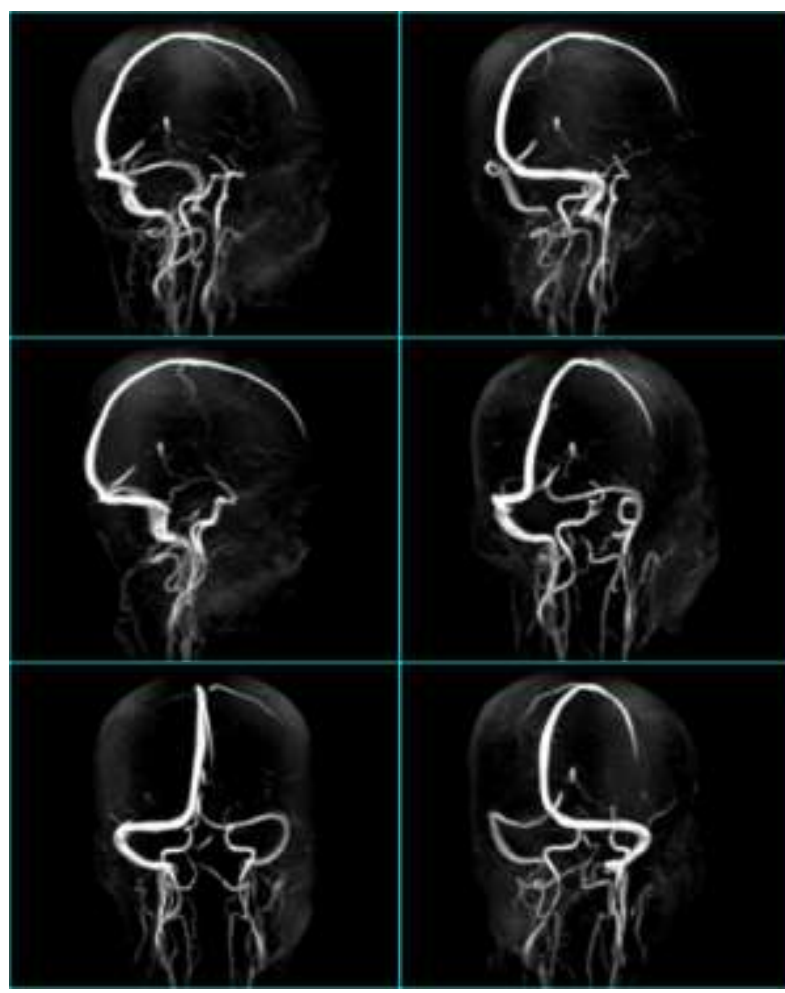

Gambar 3 .Citra MRV dengan nilai VENC $20 \mathrm{~cm} / \mathrm{dt}$

Uji beda informasi citra pada penderita Hasil penilaian dari ketiga dokter spesialis radiologi berskala ordinal, selanjutnya diuji statistik menurut kriteria anatomi dengan menggunakan SPSS 16,00 uji Friedman dilanjutkan uji Wilcoxon.

Uji beda informasi citra per kriteria pada MRV dengan penggunaan VENC $10 \mathrm{~cm} / \mathrm{dt}, 15 \mathrm{~cm} / \mathrm{dt}$ dan $20 \mathrm{~cm} / \mathrm{dt}$, beserta uji statistiknya.

Table 1.Uji Friedman per kriteria

\begin{tabular}{|c|c|c|c|c|c|}
\hline \multirow[b]{2}{*}{ Kriteria } & \multicolumn{5}{|c|}{ Hasil Penelitian } \\
\hline & $\begin{array}{l}\text { VENC } \\
10 \\
\mathrm{~cm} / \mathrm{dt}\end{array}$ & $\begin{array}{c}\text { VENC } \\
15 \\
\mathrm{~cm} / \mathrm{dt}\end{array}$ & $\begin{array}{c}\text { VENC } \\
20 \\
\mathrm{~cm} / \mathrm{dt}\end{array}$ & $\begin{array}{c}p- \\
\text { value }\end{array}$ & keterangan \\
\hline $\begin{array}{l}\text { Sinus Sagitalis } \\
\text { Superior }\end{array}$ & 102 & 109 & 114 & 0.265 & $\begin{array}{l}\text { Tidak } \\
\text { bermakna }\end{array}$ \\
\hline $\begin{array}{l}\text { Sinus } \\
\text { rectus/straight }\end{array}$ & 104 & 104 & 113 & 0.584 & $\begin{array}{l}\text { Tidak } \\
\text { bermakna }\end{array}$ \\
\hline $\begin{array}{l}\text { Sinus } \\
\text { Transversum }\end{array}$ & 91 & 114 & 117 & 0.031 & bermakna \\
\hline Vena of Galen & 114 & 99 & 101 & 0.037 & bermakna \\
\hline Sinus Sigmoid & 96 & 112 & 118 & 0.081 & $\begin{array}{l}\text { Tidak } \\
\text { bermakna }\end{array}$ \\
\hline Vena Jugularis & 81 & 108 & 125 & 0,000 & bermakna \\
\hline Total nilai & 588 & 646 & 688 & 0.032 & bermakna \\
\hline
\end{tabular}

Hasil uji freidman citra per kriteria menunjukkan nilai tingkat kepercayaan (Convident level) $95 \%(\alpha=5 \%)$ pada Sinus Transversum ( $p$-value 0.031), vena of Galen ( $p$-value $0.037)$, vena Jugularis ( $p$-value 0.000$)$, didapat $p$-value lebih 
kecil dari $\alpha \quad(\mathrm{p}<0,005)$. Maka Ho ditolak, artinya ada perbedaan informasi citra MRV pada sinus Transversum, vena of Galen dan vena Jugularis dengan variasi velocity encoding $10 \mathrm{~cm} / \mathrm{dt}, 15 \mathrm{~cm} / \mathrm{dt}, 20 \mathrm{~cm} / \mathrm{dt}$.

Sedangkan uji friedman citra per kriteria pada Sinus sagitalis superior ( $p$-value 0.265), sinus Rectus/straight ( $p$ value 0.584), sinus Sigmoid ( $p$-value 0.081) didapat $p$-value lebih besar dari $\alpha(p<0,005)$. Maka Ha ditolak, berarti tidak ada perbedaan informasi citra MRV pada sinus sagitalis superior, sinus Rectus/straight dan sinus Sigmoid dengan variasi velocity encoding $10 \mathrm{~cm} / \mathrm{dt}, 15 \mathrm{~cm} / \mathrm{dt}, 20 \mathrm{~cm} / \mathrm{dt}$.

Uji beda informasi citra secara keseluruhan pada MRV dengan penggunaan VENC $10 \mathrm{~cm} / \mathrm{dt}, 15 \mathrm{~cm} / \mathrm{dt}$ dan $20 \mathrm{~cm} / \mathrm{dt}$. Uji statistik friedman pada perbedaan informasi citra MRV secara keseluruhan mendapatkan hasil informasi citra sebagai berikut :

\begin{tabular}{ccc}
\multicolumn{3}{c}{ Tabel 2.Uji Friedman secara keseluruhan } \\
\hline Nilai Venc & p-value & keterangan \\
\hline \hline VENC $10 \mathrm{~cm} / \mathrm{dt}$ & & \\
VENC $15 \mathrm{~cm} / \mathrm{dt}$ & 0,032 & bermakna \\
VENC $20 \mathrm{~cm} / \mathrm{dt}$ & & \\
\hline
\end{tabular}

Pada uji friedman citra MRV secara keseluruhan didapat tingkat kepercayaan (Convident level) $95 \%(\alpha=5 \%)$ yaitu $p$ value lebih kecil dari $\alpha(\mathrm{p}<0,005)$ yakni sebesar 0.032 . Maka Ho ditolak, berarti ada perbedaan informasi citra MRV dengan variasi velocity encoding $10 \mathrm{~cm} / \mathrm{dt}, 15 \mathrm{~cm} / \mathrm{dt}, 20 \mathrm{~cm} / \mathrm{dt}$.

Uji beda untuk mengetahui lebih detil perbedaan keseluruhan informasi citra dengan variasi velocity encoding $10 \mathrm{~cm} / \mathrm{dt}, 15 \mathrm{~cm} / \mathrm{dt}, 20 \mathrm{~cm} / \mathrm{dt}$.

\begin{tabular}{cccc}
\multicolumn{4}{c}{ Table 3. Hasil uji Wilcoxon pada informasicitra MRV } \\
\hline & VENC & VENC & VENC \\
& $15 \mathrm{~cm} / \mathrm{dt}$ & $20 \mathrm{~cm} / \mathrm{dt}$ & $20 \mathrm{~cm} / \mathrm{dt}$ \\
$-\mathrm{VENC}$ & $-\mathrm{VENC}$ & $-\mathrm{VENC}$ \\
$10 \mathrm{~cm} / \mathrm{dt}$ & $10 \mathrm{~cm} / \mathrm{dt}$ & $15 \mathrm{~cm} / \mathrm{dt}$ \\
\hline $\mathrm{Z}$ & $-1.510^{\mathrm{a}}$ & $-1.790^{\mathrm{a}}$ & $-2.066^{\mathrm{a}}$ \\
$\begin{array}{c}\text { Asymp. Sig. } \\
\text { (2-tailed) }\end{array}$ & 0.131 & 0.073 & 0.039 \\
\hline
\end{tabular}

Hasil uji Wilcoxon pada tabel 3 memberikan hasil bahwa tidak ada perbedaan pada informasi citra antara VENC $10 \mathrm{~cm} / \mathrm{dt}$ dan VENC $15 \mathrm{~cm} / \mathrm{dt}$, serta antara VENC 10 $\mathrm{cm} / \mathrm{dt}$ dan VENC $20 \mathrm{~cm} / \mathrm{dt}$ dengan nilai signifikansi lebih dari 0,05 yaitu 0,131 dan 0,073. Sedangkan pada informasi citra MRV antara VENC $15 \mathrm{~cm} / \mathrm{dt}$ dan VENC $20 \mathrm{~cm} / \mathrm{dt}$ bahwa ada perbedaan yang signifikan karena nilai 0,039 lebih kecil dari p-value.

Hasil dari setiap penilaian terhadap informasi citra dianalisis dengan melihat mean rank untuk mengetahui informasi citra yang paling baik diantara variasi nilai VENC. Pada uji Friedman terdapat nilai mean rank untuk mengetahui informasi citra yang paling baik per kriteria antara nilai VENC $10 \mathrm{~cm} / \mathrm{dt}, 15 \mathrm{~cm} / \mathrm{dt}$ dan $20 \mathrm{~cm} / \mathrm{dt}$. Berdasarkan hasil uji tersebut didapatkan nilai mean rank sebagai berikut :
Tabel 4. Hasil mean rank uji Friedman informasi citra per kriteria

\begin{tabular}{|c|c|c|c|}
\hline \multirow[b]{2}{*}{ Kriteria } & \multicolumn{3}{|c|}{ hasil penelitian } \\
\hline & $\begin{array}{l}\text { VENC } \\
10 \\
\mathrm{~cm} / \mathrm{dt}\end{array}$ & $\begin{array}{l}\text { VENC } \\
15 \\
\mathrm{~cm} / \mathrm{dt}\end{array}$ & $\begin{array}{l}\text { VENC } \\
20 \\
\mathrm{~cm} / \mathrm{dt}\end{array}$ \\
\hline Sinus Sagitalis Superior & 1,70 & 2,03 & 2,27 \\
\hline Sinus rectus/straight & 1,93 & 1,87 & 2,20 \\
\hline Sinus Transversum & 1,47 & 2,17 & 2,37 \\
\hline Vena of Galen & 2,53 & 1,73 & 1,73 \\
\hline Sinus Sigmoid & 1,60 & 2,03 & 2,37 \\
\hline Vena Jugularis & 1,23 & 2,07 & 2,70 \\
\hline
\end{tabular}

Hasil mean rank uji Friedman informasi citra per kriteria MRV diketahui bahwa Sinus Sagitalis Superior yaitu2,27, Sinus rectus/straight yaitu 2,20, sinus transversum yaitu 2.37, sinus sigmoid yaitu 2,37, dan vena jugularis yaitu 2,70. Setiap kriteria mempunyai nilai mean rank tertinggi pada kolom VENC $20 \mathrm{~cm} / \mathrm{dt}$, kecuali vena of Galen yang diketahui mempunyai nilai mean rank tertinggi pada kolom VENC $10 \mathrm{~cm} / \mathrm{dt}$.

Pada uji Friedman terdapat nilai mean rank untuk mengetahui informasi citra yang paling baik secara keseluruhan antara nilai VENC $10 \mathrm{~cm} / \mathrm{dt}, 15 \mathrm{~cm} / \mathrm{dt}$ dan 20 $\mathrm{cm} / \mathrm{dt}$. Berdasarkan hal tersebut didapat nilai mean rank sebagai berikut:

Tabel 5.Hasil mean rank uji Friedman secara keseluruhan.

\begin{tabular}{cc}
\hline Nilai VENC & Mean Rank \\
\hline VENC $10 \mathrm{~cm} / \mathrm{dt}$ & 1.42 \\
VENC $15 \mathrm{~cm} / \mathrm{dt}$ & 1.75 \\
VENC $20 \mathrm{~cm} / \mathrm{dt}$ & 2.83 \\
\hline
\end{tabular}

Tabel 6 Hasil uji Wilcoxon informasi citra MRV

\begin{tabular}{|c|c|c|c|c|}
\hline & & $\mathrm{N}$ & $\begin{array}{l}\text { Mean } \\
\text { Rank }\end{array}$ & $\begin{array}{c}\text { Sum of } \\
\text { Ranks }\end{array}$ \\
\hline \multirow{4}{*}{$\begin{array}{l}\text { VENC } 15 \mathrm{~cm} / \mathrm{dt} \\
- \text { VENC } 10 \\
\mathrm{~cm} / \mathrm{dt}\end{array}$} & $\begin{array}{l}\text { Negative } \\
\text { Ranks }\end{array}$ & $4^{a}$ & 7.12 & 28.50 \\
\hline & $\begin{array}{l}\text { Positive } \\
\text { Ranks }\end{array}$ & $10^{\mathrm{b}}$ & 7.65 & 76.50 \\
\hline & Ties & $1^{\mathrm{c}}$ & & \\
\hline & Total & 15 & & \\
\hline \multirow{4}{*}{$\begin{array}{l}\text { VENC } 20 \mathrm{~cm} / \mathrm{dt} \\
- \text { VENC } 10 \\
\mathrm{~cm} / \mathrm{dt}\end{array}$} & $\begin{array}{l}\text { Negative } \\
\text { Ranks }\end{array}$ & $4^{\mathrm{d}}$ & 7.12 & 28.50 \\
\hline & $\begin{array}{l}\text { Positive } \\
\text { Ranks }\end{array}$ & $11^{\mathrm{e}}$ & 8.32 & 91.50 \\
\hline & Ties & $0^{\mathrm{f}}$ & & \\
\hline & Total & 15 & & \\
\hline \multirow{4}{*}{$\begin{array}{l}\text { VENC } 20 \mathrm{~cm} / \mathrm{dt} \\
- \text { VENC } 15 \\
\mathrm{~cm} / \mathrm{dt}\end{array}$} & $\begin{array}{l}\text { Negative } \\
\text { Ranks }\end{array}$ & $3^{g}$ & 5.33 & 16.00 \\
\hline & $\begin{array}{l}\text { Positive } \\
\text { Ranks }\end{array}$ & $10^{\mathrm{h}}$ & 7.50 & 75.00 \\
\hline & Ties & $2^{i}$ & & \\
\hline & Total & 15 & & \\
\hline
\end{tabular}


Berdasarkan tabel 5 didapatkan hasil informasi citra anatomi secara keseluruhan pada pemeriksaan MRV dengan penggunaan VENC $10 \mathrm{~cm} / \mathrm{dt}$ adalah 1,42, pada VENC 15 $\mathrm{cm} / \mathrm{dt}$ memiliki mean rank lebih tinggi yaitu 1,75 . Sedangkan pada VENC $20 \mathrm{~cm} / \mathrm{dt}$ terdapat mean rank tertinggi yaitu sebesar 2.83 .

Pada uji Wilcoxon terdapat nilai mean rank untuk mengetahui lebih detil informasi citra yang paling baik antara nilai VENC $10 \mathrm{~cm} / \mathrm{dt}$ dan VENC $15 \mathrm{~cm} / \mathrm{dt}$, antara VENC 10 $\mathrm{cm} / \mathrm{dt}$ dan VENC $20 \mathrm{~cm} / \mathrm{dt}$ dan antara VENC $15 \mathrm{~cm} / \mathrm{dt}$ dan VENC $20 \mathrm{~cm} / \mathrm{dt}$.

Tabel 6 menunjukkan bahwa berdasarkan negatif dan positif rank antara $10 \mathrm{~cm} / \mathrm{dt}$ dan $15 \mathrm{~cm} / \mathrm{dt}, 10 \mathrm{~cm} / \mathrm{dt}$ dan 20 $\mathrm{cm} / \mathrm{dt}$, VENC $15 \mathrm{~cm} / \mathrm{dt}$ dan $20 \mathrm{~cm} / \mathrm{dt}$ terdapat informasi bahwa ada perbedaan antara VENC yang diujikan yaitu 0,53 dan 1.2. Perbedaan paling besar pada VENC $15 \mathrm{~cm} / \mathrm{dt}$ dan 20 $\mathrm{cm} / \mathrm{dt}$, yaitu sebesar 2,17

\section{DISKUSI}

Dalam penelitian ini menghasilkan informasi citra MRV dengan penerapan VENC yang bervariasi yaitu $10 \mathrm{~cm} / \mathrm{dt}, 15$ $\mathrm{cm} / \mathrm{dt}, 20 \mathrm{~cm} / \mathrm{dt}$. Hasil informasi tersebut dinilai oleh 3 dokter speialis radiologi. Penilaian kuesioner oleh responden tersebut berupa data ordinal dan diolah secara statistik dengan uji non parametrik Friedman, baik secara tiap kriteria maupun secara keseluruhan. Kemudian hasil penelitian diuji Wilcoxon untuk mendapatkan nilai perbedaan yang lebih detil di setiap nilai VENC.

Hasil uji statistik menyatakan bahwa : Berdasarkan hasil SPSS uji statistik non parametrik Friedman menyatakan ada perbedaan yang signifikan untuk kriteria sinus transversum, vena of Galen, dan vena jugularis dengan penggunaan VENC yang bervariasi yaitu $10 \mathrm{~cm} / \mathrm{dt}, 15 \mathrm{~cm} / \mathrm{dt}, 20 \mathrm{~cm} / \mathrm{dt}$. Dengan nilai kemaknaan (p-value) pada kriteria anatomi sinus transversum yaitu 0.031 , vena of Galen yaitu 0.037 , dan vena jugularis yaitu 0.000. Sedangkan pada kriteria anatomi Sinus Sagitalis Superior yaitu 0.265, Sinus rectus/straight yaitu 0.584 , sinus sigmoid yaitu 0.081 menunjukkan bahwa nilai kemaknaan ( $p$-value) lebih besar dari 0,05. Sehingga Ho diterima, artinya tidak ada perbedaan yang signifikan untuk kriteria anatomi Sinus Sagitalis Superior, Sinus rectus/straight, dan sinus sigmoid.

Perbedaan tersebut disebabkan karena kecepatan aliran darah vena tidak bisa dikompensasi oleh nilai VENC yang terlalu rendah. Karena menurut Schaller saat ini variasi kecepatan di vena jugularis antara $30-50 \mathrm{~cm} / \mathrm{dt}$. Bila jumlah darah yang melalui pembuluh adalah konstan, kecepatan darah akan berkurang dengan meningkatnya diameter pembuluh darah. Darah yang mengalir akan mengalami hambatan terutama yang mengalir berdekatan dengan dindingnya (Guyton, 1993). Menurut penulis nilai VENC rendah hanya menampilkan aliran yang berdekatan dengan dinding pembuluh saja. sehingga kejelasan informasi citra hampir sama atau perbedaan tidak signifikan karena dievaluasi dari aliran darah yang berdekatan dengan dindingnya.

Kaliber Sinus Sagitalis Superior, Sinus rectus/straight, sinus sigmoid tidak sebesar sinus transversum, dan vena jugularis sehingga kejelasan informasi citra dievaluasi hampir sama atau perbedaannya tidak signifikan. Sedangkan pada sinus transversum, dan vena jugularis, karena kalibernya lebih besar sehingga terjadi perbedaan kejelasan informasi citra yang signifikan. Sedangkan vena of Galen adalah muara dari vena basalis, vena Rosenthal dan vena cerebral internal, sehingga pada VENC $10 \mathrm{~cm} / \mathrm{dt}$ informasi citra lebih jelas dibanding VENC $15 \mathrm{~cm} / \mathrm{dt}$ maupun $20 \mathrm{~cm} / \mathrm{dt}$.

Perbedaan informasi citra menurut uji Wilcoxon antara VENC $10 \mathrm{~cm} / \mathrm{dt}$ dan VENC $15 \mathrm{~cm} / \mathrm{dt}$ maupun $10 \mathrm{~cm} / \mathrm{dt}$ dan 20 $\mathrm{cm} / \mathrm{dt}$ tidak signifikan, menurut penulis meskipun secara statistik tidak ada perbedaan yang signifikan, hal tersebut karena perbedaan nilai subyektif tipis namun secara kuantitatif hasil penilaian lebih banyak pada VENC $20 \mathrm{~cm} / \mathrm{dt}$ dibandingkan VENC $10 \mathrm{~cm} / \mathrm{dt}$ dan $15 \mathrm{~cm} / \mathrm{dt}$.

Informasi citra yang paling baik pada MRV yang paling baik dengan penggunaan variasi nilai VENC $10 \mathrm{~cm} / \mathrm{dt}, 15$ $\mathrm{cm} / \mathrm{dt}, 20 \mathrm{~cm} / \mathrm{dt}$ didapatkan dari hasil mean rank pada uji non parametrik friedman per kriteria citra (tabel 4) yaitu sinus Sagitalis superior, Sinus rectus/straight, sinus transversum, sinus sigmoid, vena jugularis didapatkan hasil mean rank tertinggi sinus sagitalis superior, Sinus rectus/straight, sinus transversum, sinus sigmoid, vena jugularis pada VENC 20 $\mathrm{cm} / \mathrm{dt}$ dibanding VENC $10 \mathrm{~cm} / \mathrm{dt}$ dan VENC $15 \mathrm{~cm} / \mathrm{dt}$. Penulis berpendapat karena kecepatan aliran pada sinus Sagitalis superior, Sinus rectus/straight, sinus transversum, sinus sigmoid, vena jugularis bisa dikompensasi oleh Bipolar Gradient dengan pengaplikasian VENC $20 \mathrm{~cm} / \mathrm{dt}$, sehingga ketidakjelasan sinyal saat pergeseran phase shif bisa dikurangi. Sedangkan pada vena of Galen informasi citra lebih jelas, ditunjukkan oleh nilai mean rank 2,53 tertinggi pada VENC $10 \mathrm{~cm} / \mathrm{dt}$ dibandingkan dengan VENC $15 \mathrm{~cm} / \mathrm{dt}$ maupun $20 \mathrm{~cm} / \mathrm{dt}$. Menurut penulis hal ini disebabkan oleh Vena of Galen merupakan muara dari vena basalis, vena Rosenthal dan vena cerebral internal, sehingga kecepatan aliran lebih yang rendah bisa dikompensasi oleh bipolar gradient dengan menggunakan VENC $10 \mathrm{~cm} / \mathrm{dt}$

Dari tabel 5 tentang hasil mean rank uji Friedman informasi citra secara keseluruhan, maka informasi citra MRV dengan penggunaan VENC $10 \mathrm{~cm} / \mathrm{dt}, 15 \mathrm{~cm} / \mathrm{dt}, 20 \mathrm{~cm} / \mathrm{dt}$ untuk melihat kriteria keseluruhan lebih baik menggunakan VENC $20 \mathrm{~cm} / \mathrm{dt}$ karena memiliki mean rank tertinggi dibandingkan VENC $10 \mathrm{~cm} / \mathrm{dt}$ maupun $15 \mathrm{~cm} / \mathrm{dt}$, yakni sebesar 2,83. Nilai tersebut menunjukkan bahwa informasi citra MRV pada VENC $20 \mathrm{~cm} / \mathrm{dt}$ adalah yang paling baik dibanding VENC $10 \mathrm{~cm} / \mathrm{dt}$ dan $15 \mathrm{~cm} / \mathrm{dt}$. Penulis menyimpulkan bahwa untuk menganalisa kejelasan anatomi sinus Sagitalis superior, Sinus rectus/straight, sinus transversum, sinus sigmoid, vena jugularis lebih baik menggunakan VENC $20 \mathrm{~cm} / \mathrm{dt}$. Sedangkan untuk melihat kejelasan anatomi vena of Galen dapat menggunakan VENC $10 \mathrm{~cm} / \mathrm{dt}$.

\section{SIMPULAN}

Penerapan Velocity Encoding memberikan perbedaan sinyal pada sistem vena kepala. Ketidaktepatan penerapan memberikan perbedaan dalam penilaian informasi citra. Hal 
ini sesuai dengan penelitian tentang variasi nilai Velocity Encoding pada MRV terhadap 15 penderita tumor kepala. Terdapat perbedaan yang signifikan antara nilai VENC 10 $\mathrm{cm} / \mathrm{dt}, 15 \mathrm{~cm} / \mathrm{dt}$ dan $20 \mathrm{~cm} / \mathrm{dt}$ terhadap penilaian informasi citra oleh 3 responden yang berkompeten di bidang MRI. Pada perhitungan secara statistik SPSS uji friedman citra MRV secara keseluruhan didapat tingkat kepercayaan (Convident level) $95 \%(\alpha=5 \%)$ yaitu $p$-value lebih kecil dari $\alpha$ $(\mathrm{p}<0,005)$ yakni sebesar 0.032. Sehingga Ho ditolak dan Ha diterima, yang artinya ada perbedaan informasi citra Magnetic Resonance Venography dengan variasi velocity encoding 10 $\mathrm{cm} / \mathrm{dt}, 15 \mathrm{~cm} / \mathrm{dt}, 20 \mathrm{~cm} / \mathrm{dt}$. Perbedaan informasi citra menurut uji Wilcoxon antara VENC $10 \mathrm{~cm} / \mathrm{dt}$ dan VENC $15 \mathrm{~cm} / \mathrm{dt}$ maupun $10 \mathrm{~cm} / \mathrm{dt}$ dan $20 \mathrm{~cm} / \mathrm{dt}$ tidak signifikan. Sedangkan pengujian $15 \mathrm{~cm} / \mathrm{dt}$ dan $20 \mathrm{~cm} / \mathrm{dt}$ memberikan perbedaan yang signifikan, Menurut penulis meskipun secara statistik tidak ada perbedaan signifikan, hal tersebut karena perbedaan nilai subyektif tipis namun secara kuantitatif hasil penilaian lebih banyak pada VENC $20 \mathrm{~cm} / \mathrm{dt}$ dibandingkan VENC $10 \mathrm{~cm} / \mathrm{dt}$ dan $15 \mathrm{~cm} / \mathrm{dt}$.

Hasil informasi citra yang paling baik pada MRV dengan variasi velocity encoding $10 \mathrm{~cm} / \mathrm{dt}, 15 \mathrm{~cm} / \mathrm{dt}, 20 \mathrm{~cm} / \mathrm{dt}$ adalah informasi citra MRV yang dihasilkan oleh VENC $20 \mathrm{~cm} / \mathrm{dt}$ ditunjukkan dengan mean rank 2,83. Sementara mean rank untuk VENC $10 \mathrm{~cm} / \mathrm{dt}$ dan $15 \mathrm{~cm} / \mathrm{dt}$ hanya 1,42 dan 1,75. Karena Sinus Sagitalis Superior, sinus rectus/straight, sinus transversum, sinus sigmoid, dan vena jugularis tampak jelas pada VENC $20 \mathrm{~cm} / \mathrm{dt}$. Sedangkan Vena of Galen mempunyai total nilai tertinggi pada VENC $10 \mathrm{~cm} / \mathrm{dt}$. Namun secara keseluruhan nilai VENC yang memberikan informasi citra terbaik adalah $20 \mathrm{~cm} / \mathrm{dt}$.

\section{DAFTAR PUSTAKA}

American Cancer Society. 2016. Cancer Facts and Figures. Atlanta, Ga: American Cancer Society.

Ayanzen, RH, Bird CR, Keller PJ, McCully FJ, Theobald MR, Heiserman JE. 2000. Cerebral MR venography: normal anatomy and potential diagnostic pitfalls.

Choi, Changho, Sandeep K Ganji, Ralph J DeBerardinis, Kimmo J Hatanpaa, Dinesh Rakheja, Zoltan Kovacs, Xiao-Li Yang, Tomoyuki Mashimo, Jack M Raisanen, Isaac Marin-Valencia, Juan M Pascual, Christopher J Madden, Bruce E Mickey, Craig R Malloy, Robert M Bachoo \& Elizabeth A Maher. 2012. 2-hydroxyglutarate detection by magnetic resonance spectroscopy in IDH-mutated patients withgliomas.

Chuo, Lao Sieng, Mahmud Rozy, Salih Qussay A. 2004. Color Doppler Ultrasound Examination Of The Main Portal Vein And Inferior Vena Cava In Normal Malaysian Adult Population: A Fasting And Post Prandial Evaluation Volume 2 number 2.

Glockner, James F, Christine U. Lee. 2010. Magnetic Resonance Venography, Radiol. 39(6):36-42.

Guyton, A C, 1993, Fisiologi Tubuh Manusia Jilid I edisi 9, diterjemahkan oleh Dra. FI Harijadi, Dr. Soerjani Soejono, Dr. Budiharto Raharjo MS, Dr. Gunawan Arifin.

Hartsdale Imaging and MedNet Technologies. 2014. MR angiography (MRA) and MR venography (MRV), Inc. All Rights Reserved. MedNetSites ${ }^{\text {TM}}$-Powered by MedNet Technologies, Inc

Hesselink, John R. 2010. Fundamentals Of Mr Spectroscopy. https://mrimaster.com/index-3.html
Jerrolds, Jennifer, Keene Shane. 2009. MRI Safety at 3T versus 1.5T: The Internet Journal of World Health and Societal Politics, Volume 6 , Number 1.

Jinhee, Jang, Bum-Soo Kim, MD Bom-Yi KimHyun Seok Choi, So-Lyung Jung, and Kook-Jin Ahn. 2015. Subtraction MR Venography Acquired from Time-Resolved Contrast-Enhanced MR Angiography: Comparison with Phase-Contrast MR Venography and Single-Phase Contrast-Enhanced MR Venography. Korean J Radiol.

Khuntia Deepak, Brown Paul, Li Jing, Mehta Minesh P. 2006. Journal of Clinical Oncology Whole-Brain Radiotherapy in the Management of Brain Metastasis

Pomschar Andreas, Koerte Inga,Sang Lee,Ruediger P. Laubender, Andreas Straube, Florian Heinen, Birgit Ertl-Wagner, Noam Alperin. 2013. MRI Evidence for Altered Venous Drainage and Intracranial Compliance in Mild Traumatic Brain Injury

Schaller B. 2004. Physiology of cerebral venous blood flow: from experimental data inanimals to normal function in humans, MaxPlanck-Institute for Neurological Research, Available online 13 November 2004, Gleueler Strasse 50, D-50931 Cologne, Germany

Stoquart ElSankari Souraya, Pierre Lehmann, Agnes Villette, Marek Czosnyka, Marc-Etienne Meyer, Herve Deramond, Olivier Baledent. 2009. A phase-contrast MRI study of physiologic cerebral venous flow.

Trinh Jennifer, Pandit Rajul, Patel Mahesh R, 2012, Pictorial Review of Intracranial MRV techniques, pitfalls, and common pathologies involving the cerebral venous system 